\title{
Measurement of Mitochondrial pH In Situ
}

BioTechniques 30:804-815 (April 2001)

\section{Akiyuki Takahashi, Yingpei Zhang, Victoria E. Centonze, and Brian Herman}

University of Texas Health Science Center at San Antonio, San Antonio, TX, USA

\section{INTRODUCTION}

Mitochondria play a pivotal role in both the life and death of cells. On the one hand, they serve as the primary source of aerobic energy production in cells. The $\mathrm{pH}$ gradient $\left(\Delta \mathrm{pH}_{\mathrm{m}}\right)$ across the inner mitochondrial membrane (alkaline inside) and the inner mitochondrial membrane potential $\left(\Delta \varphi_{\mathrm{m}}\right)$ make up the electrochemical gradient, which regulates the efficiency of ATP synthesis and other mitochondrial activity [e.g., $\mathrm{Na}^{+} / \mathrm{Ca}^{2+}$ exchange, $\mathrm{K}^{+} / \mathrm{H}^{+}$antiport, transhydrogenation, etc. (35, 42)]. Alteration in mitochondrial $\mathrm{pH}$ has also been hypothesized to modulate mitochondrial apoptosis (programmed cell death). Cytochrome $\mathrm{c}$ is known to be released from mitochondria into the cytosol by several apoptotic stimuli, resulting in the activation of caspases that cause cell death via apoptosis $(15,26$, $39,41,90)$. The release of cytochrome $\mathrm{c}$ from mitochondria has been hypothesized to occur following the functional uncoupling of the mitochondria caused by the formation of a nonspecific pore in the inner mitochondrial membrane, termed the mitochondrial permeability pore (MPP) $(5,29,32,46,47,62,85,89$, 91). The opening of the MPP has been hypothesized to be regulated by mitochondrial $\mathrm{pH}$. Accordingly, the measurement of mitochondrial matrix $\mathrm{pH}$ $\left(\mathrm{pH}_{\mathrm{m}}\right)$ is essential for understanding the regulation of normal and pathological mitochondrial function.

One of the most popular methods for the analysis of $\mathrm{pH}_{\mathrm{n}}$ has been to use isolated mitochondria $(3,6,16,30,37,56$, $65,74)$. This approach has contributed substantially to our understanding of the role of $\mathrm{pH}_{\mathrm{m}}$ in mitochondrial function. However, this method requires isolated mitochondria; thus, it is difficult to observe and quantitate spatial and temporal alterations in $\mathrm{pH}_{\mathrm{m}}$ as they relate to mitochondrial and cellular physiology at the individual mitochondrial level in situ (33). In addition, it has been reported that experimental results obtained using isolated mitochondria can differ from results obtained in situ $(7,43)$.

The distribution of non-metabolizable lipophilic cations and weak acids or bases has been used for the determination of the mitochondrial transmembrane potential $\left(\Delta \varphi_{\mathrm{m}}\right)$ and $\Delta \mathrm{pH}_{\mathrm{m}}$ in situ $(19,36,77)$. The weak acid 5,5'-demethyloxazolidine-2,4-dione (DMO) distributes across the mitochondrial mem brane according to $\Delta \mathrm{pH}_{\mathrm{m}}(1,34)$. Thus, $\Delta \mathrm{pH}_{\mathrm{m}}$ can be evaluated by quantitating the radiolabeled DMO in the mitochondrial compartment after separation from other cellular components. Unfortunately, because DMO requires at least $15 \mathrm{~min}$ to equilibrate throughout cells, this method can only be used to monitor steady-state changes in $\Delta \mathrm{pH}_{\mathrm{m}}$ $(36,77)$. This approach also requires the isolation of mitochondria; thus, it is not possible to monitor $\mathrm{pH}_{\mathrm{m}}$ in situ.

The most popular method for monitoring subcellular ion concentrations in situ in intact cells or tissues has been optical microscopy. Historically, $\mathrm{Ca}^{2+}$ was the first ion to be measured in cells with this approach, and such measurements allowed both spatial and temporal determination of cellular $\mathrm{Ca}^{2+}$ to be quantitated under a variety of normal and abnormal conditions (21). Over the past decade, refinements in these approaches have targeted measurements of $\mathrm{Ca}^{2+}$ dynamics to specific organelles including the nucleus, mitochondria, and endoplasmic reticulumvarious techniques to monitor free $\mathrm{Ca}^{2+}$ concentration $\left(\left[\mathrm{Ca}^{2+}\right]\right)$ in these specific compartments in situ have been established. For measurements of mitochondrial $\left[\mathrm{Ca}^{2+}\right]\left(\left[\mathrm{Ca}^{2+}\right]_{\mathrm{m}}\right)$ specifically, investigators have used: ( $i$ ) Rhod- 2 or $\mathrm{X}$-rhod-1, which accumulates into the 
mitochondria as a function of $\Delta \varphi_{\mathrm{m}}$ $(51,81)$; (ii) preferentially quenching $\mathrm{Ca}^{2+}$-sensitive cytosolic (but not mitochondrial) reporter fluorescence with metal ions such as $\mathrm{Mn}^{2+}$ or $\mathrm{Co}^{2+}(53)$; (iii) co-staining cells with both a $\mathrm{Ca}^{2+}$ indicator and a mitochondrial marker to demonstrate which portion of the emitted $\mathrm{Ca}^{2+}$-sensitive fluorescence is localized to mitochondria $(11,63)$; (iv) loading $\mathrm{Ca}^{2+}$ indicators preferentially into mitochondria by manipulating the loading conditions [e.g., temperature, pre-loading and post-loading incubation times, and dye concentration (72,76)]; (v) targeting $\mathrm{Ca}^{2+}$-sensitive reporter molecules such as the $\mathrm{Ca}^{2+}$ sensitive photoprotein aequorin to mitochondria $(66,67,69)$; and most recently, (vi) targeting $\mathrm{Ca}^{2+}$-sensitive mutant GFP fluorescence resonance energy transfer (FRET) fusion protein constructs to mitochondria $(54,55,61,73)$. Two such constructs have been produced: cameleons, which have been difficult to target specifically to mitochondria (they often mistarget to the cytoplasm), and Camgaroos, which appear to target much more specifically to the mitochondria and to provide accurate assessment of mitochondrial $\mathrm{Ca}^{2+}$.

While numerous approaches to the measurement of $\left[\mathrm{Ca}^{2+}\right]_{m}$ have been developed, the technology for the measurement of mitochondrial $\mathrm{pH}$ has not progressed as rapidly. The approaches developed for the measurement of $\left[\mathrm{Ca}^{2+}\right]_{\mathrm{m}}$ can be applied to measurements of $\mathrm{pH}_{\mathrm{m}}$. Here, we describe some of the newer optical imaging-based approaches available to measure $\mathrm{pH}_{\mathrm{m}}$.

\section{Measurement of Mitochondrial pH Using Laser Scanning Confocal or Multiphoton Microscopy}

Fluorescein has been one of the most popular indicators for the measurement of $\mathrm{pH}$ in situ because its emission is $\mathrm{pH}$-sensitive. Initially employed with widefield microscopes, fluorescein has more recently been used with confocal scanning laser microscopy (CLSM) because of the higher spatial resolution offered by this approach (70). Cells are normally loaded with a membrane-permeable form of fluorescein. Following loading, cells are incubated under conditions that allow the membrane-permeable form of fluorescein to enter intracellular compartments (i.e., mitochondria). Subsequent hydrolysis of the fluorescein derivative results in the formation of a negatively charged fluorescein molecule, which is then trapped in the cytoplasm and any organelle into which it entered before hydrolysis. In many cells, negatively charged, cytosolically localized fluorescein can be pumped out of the cell via an anion transporter, leaving organelletrapped (i.e., mitochondria) fluorescein behind. Because fluorescein distributes relatively freely in the cell according to the $\mathrm{pH}$ gradient $(77,78,80)$, the concentration in the mitochondria is thought to be 80 - to 100 -fold higher than the concentration in the cytosol when the $\Delta \mathrm{pH}_{\mathrm{m}}$ is 1.0 (78). While this allows a large signal to be recorded from the mitochondria specifically, accurate measurement of $\mathrm{pH}_{\mathrm{m}}$ is difficult because both its concentration and fluorescence change as a function of $\Delta \mathrm{pH}_{\mathrm{m}}$.

This is one of the reasons why ratiometric $\mathrm{pH}$ indicators have been a welcome addition to the armamentarium for accurate measurement of $\mathrm{pH}_{\mathrm{m}}$. The most popular fluorescent $\mathrm{pH}$-sensitive probes for measuring $\mathrm{pH}_{\mathrm{m}}$ in living cells and isolated mitochondria are the ratiometric indicators such as BCECF and carboxy-SNARF $(3,37)$. The combination of carboxy SNARF and CLSM or multiphoton laser scanning microscopy (MPLSM) has proven particularly useful in the measurement of $\mathrm{pH}_{\mathrm{m}}(12,18,45)$. When using CLSM, dual-emission ratiometry is preferred over dual-excitation ratiometry because most CLSMs have at least two (and usually more) photomultiplier tubes and can detect fluorescence emission signals at different wavelengths simultaneously. It is very difficult for most CLSMs to perform dual-excitation ratiometry because they cannot change excitation wavelengths quick enough for physiological measurements.

Carboxy SNARF-1 is a $\mathrm{pH}$-sensitive fluorophore with a $\mathrm{pKa}$ of approximately 7.5 , which makes it suitable for measuring $\mathrm{pH}_{\mathrm{m}}$ (2). The fluorescenceisobestic point of carboxy SNARF-1 is approximately $600 \mathrm{~nm}$, and the ratio of fluorescence emission detected at wavelengths greater than $610 \mathrm{~nm}$ relative to that at $580 \mathrm{~nm}$ (when excited at
$488 \mathrm{~nm}$ ) undergoes a dramatic change as a function of $\mathrm{pH}$. Carboxy SNARF is one of the most appropriate $\mathrm{pH}$ sensors for use with CLSM because it has a broad absorbance spectrum and displays $\mathrm{pH}$-dependent alterations in its emission spectrum. For example, carboxy-SNARF can be excited at 488 , 514 , or $568 \mathrm{~nm}$, making it suitable for use with CLSM argon, green $\mathrm{HeNe}$, and krypton-argon lasers, respectively. When excited by 488 or $514 \mathrm{~nm}$, carboxy SNARF exhibits an isosbestic point at $610 \mathrm{~nm}$; it also exhibits higher emission intensity when excited at 514 $\mathrm{nm}$ compared to $488 \mathrm{~nm}$. When excited at $568 \mathrm{~nm}$, carboxy SNARF-1 demonstrates an isosbestic point at $585 \mathrm{~nm}$ and $\mathrm{pH}$-dependent changes in emission intensity at $640 \mathrm{~nm}$.

Successful use of carboxy-SNARF for measuring $\mathrm{pH}_{\mathrm{m}}$ requires mitochondrial localization of the fluorophore. Because cells are normally loaded with the membrane-permeable acetoxymethy (AM) ester form of carboxy SNARF, the ultimate intracellular distribution of the indicator is dependent on the activity of cytosolic and organelle esterases relative to the rate of uptake of the AM form of the dye into the cytosol and organelles (72).

The use of carboxy-SNARF has its drawbacks. One potential problem is if the $\mathrm{pH}$ of the mitochondria and the surrounding cytosol are similar, it may be difficult to distinguish mitochondria from cytosol, based on $\mathrm{pH}$-dependent differences in the emission ratio image. As demonstrated in the studies of Chacon et al. (12), normal mitochondria can be easily distinguished from the surrounding cytosol. However, if $\mathrm{pH}_{\mathrm{m}}$ decreases significantly, then the difference between the $\mathrm{pH}$ of the cytosol and the mitochondria becomes much smaller, making it more difficult to distinguish mitochondria from cytosol and accurately measure the $\mathrm{pH}_{\mathrm{n}}$. An additional concern is that mitochondria are motile organelles in cells, constantly moving and changing shape under physiological conditions (4). For both of these reasons, either information pertaining to mitochondrial localization must be obtained at the same time as $\mathrm{pH}$-sensitive ratiometry is performed or loading of carboxy SNARF-1 must be mitochondria-specific. 
To address the first of these concerns, it is possible to stain the mitochondria with a mitochondrial-specific fluorescent probe whose spectral properties are distinct from those of carboxy SNARF (11). Since the major emission of carboxy-SNARF occurs in the red wavelength, it is possible to use a green wavelength emitting mitochondrial-specific dye, such as $\mathrm{DiOC}_{6}(3)$, or MitoTracker Green FM $^{\mathrm{TM}}$ (Molecular Probes, Eugene, OR, USA), as a specific maker of mitochondria. $\mathrm{DiOC}_{6}(3)$ is one of the most popular indicators for the measurement of $\Delta \varphi_{\mathrm{m}}$, whereas MitoTracker Green FM stains mitochondria independent of $\Delta \varphi_{\mathrm{m}}(27,83)$. Carboxy SNARF1 and either $\mathrm{DiOC}_{6}(3)$ or MitoTracker Green FM can be excited with the 488$\mathrm{nm}$ line of an argon laser or a multiphoton-excitation laser, allowing simultaneous acquisition of images for the morphological identification of mitochondria and the determination of $\Delta \mathrm{pH}_{\mathrm{m}}$ (Figure 1). To estimate mitochondrial $\mathrm{pH}$, the image obtained at 560-600 nm (Figure 1B) would be divided (ratioed) by the image obtained at greater than $610 \mathrm{~nm}$ (Figure 1C). Pixels representing mitochondria would then be determined by overlaying the resultant ratio image with the $\mathrm{DiOC}_{6}(3)$ image and selecting those pixels in the ratio image that contained intensity in $\mathrm{DiOC}_{6}(3)$ image. Because the carboxy-SNARF is also local- ized to the cytosol, an added benefit of this approach is that in addition to being able to measure mitochondrial $\mathrm{pH}$ and $\Delta \varphi_{\mathrm{m}}$, simultaneous measurement of cytosolic and mitochondrial $\mathrm{pH}$ is also possible. One caveat is that if MitoTracker dyes are used to identify mitochondria, these probes can be toxic to cells, so care is required in their usage.

Mitochondrial-specific loading of carboxy SNARF-1 takes advantage of the fact that many cells contain anion transporters in their plasma membrane. These plasma membrane proteins can transport negatively charged, cytosolically localized fluorescent dyes out of cells (81). Post-incubation of carboxySNARF (and cells loaded with other fluorescent probes) at $37^{\circ} \mathrm{C}$ or room temperature for a number of hours results in the loss of cytosolically localized fluorescent dyes but retains mitochondrial (and other organelle) accumulated probes intact (Figure 2).

\section{Measurement of Mitochondrial pH Using GFP}

GFP, isolated from the jellyfish $A e$ quorea victoria, has been used extensively as a fluorescent label in molecular and cell biology. Over the past five years, numerous applications of GFP have been described in several reviews $(23,25,28,44,52,64,82)$. The most im portant feature of GFP is that it can be expressed as a targetable fusion protein in cells, tissues, and whole animals, thereby providing an endogenous marker of the location and environmental context of specific proteins and components in intact living cells. Mutation of wild-type GFP has resulted in the development of spectrally distinct mutants of GFP that have further extended this molecule's usefulness.

It has been known for some time that the absorption and emission of various GFP mutants are $\mathrm{pH}$-sensitive, although to differing degrees (86-88). The emission intensity of most GFP mutants decreases with lowered $\mathrm{pH}$, while some GFPs, including the wild-type (88), have two major absorption peaks that demonstrate opposite $\mathrm{pH}$-dependent effects upon the absorption of a photon. The $\mathrm{pH}$ sensitivity of the GFP emission is thought to be due to $\mathrm{pH}$-dependent effects on the absorption process rather than any alternation in quantum yield (40). The pH-dependent change in the absorption/emission characteristics of GFP is caused by protonation of the chromophore portion of the protein $(24,57)$, which occurs extremely rapidly and is reversible in the $\mathrm{pH}$ range between 5 and $12(14,40,59,86,87)$.

Recently, there have been reports that take advantage of the $\mathrm{pH}$ sensitivity of the different GFP variants to mon-

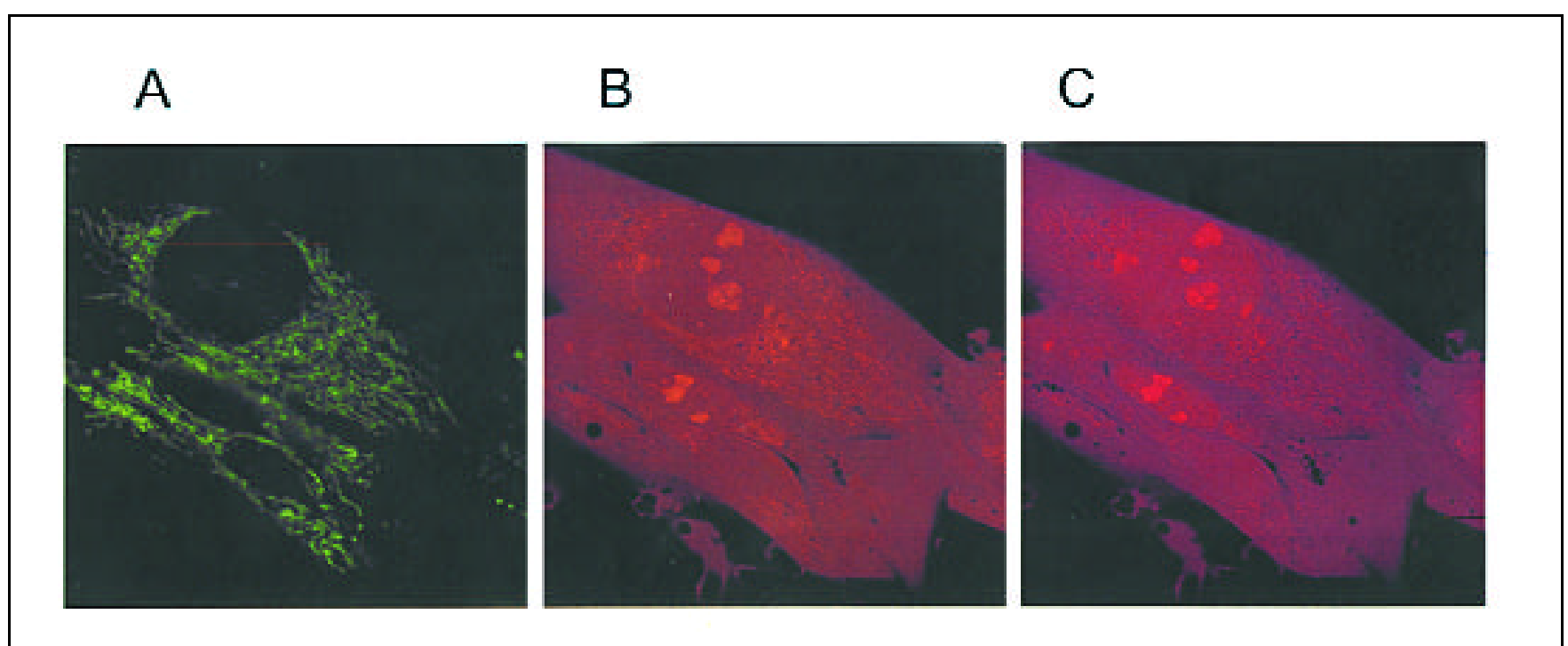

Figure 1. Multiphoton imaging of BHK cells co-stained with DiOC $(3)$ and carboxy SNARF-1/AM. The excitation wavelength of $850 \mathrm{~nm}$ was provided by a Coherent 5 W Verdi pump laser used to excite a fs Ti:Sapphire laser (Coherent, Santa Clara, CA, USA). The fluorescence emitted was collected through appropriate dichroic mirrors and filters. (A) Fluorescent image detected via 505-525-nm bandpass filter for DiOC (3). (B) Fluorescent image detected via 560-600-nm bandpass filter for carboxy SNARF-1. (C) Fluorescent image detected via 610-nm longpass filter for carboxy SNARF-1. 
itor local $\mathrm{pH}$ in mitochondria, the Golgi, and the secretory pathway $(40,49,50)$. This approach may be the most ideal method for measuring organelle $\mathrm{pH}$ because $\mathrm{pH}$-dependent GFP fusion proteins can be targeted to specific intracellular organelles without affecting organelle function. However, it is important with any fluorescent $\mathrm{pH}$ probe to consider the $\mathrm{pKa}$ of the particular GFP mutant being used, as it should be optimally matched to the $\mathrm{pH}$ to be monitored in the organelle. For example, the $\mathrm{pKa}$ of enhanced green fluorescent protein (EGFP) has been reported to be approximately 6.0 (Figure 3) $(24,31,40,49)$. This makes this particular GFP variant a good monitor of the slightly acidic $\mathrm{pH}$ found in the
Golgi and secretory pathways (50) but precludes its use as a monitor of $\mathrm{pH}_{\mathrm{m}}$, which is much more alkaline. Cyan fluorescent protein (CFP) emission is reported to be relatively less $\mathrm{pH}$-sensitive, while yellow fluorescent protein (YFP) displays more $\mathrm{pH}$ sensitivity than wild-type GFP $(24,49)$. Moreover, the pKa of YFP has been reported to be approximately 7.0 (compared to approximately 6.0 for EGFP), making YFP potentially more useful for measuring $\mathrm{pH}_{\mathrm{m}}$ (Figure $\left.3 \mathrm{~A}\right)(24,49,84)$.

While the fluorescent intensity of the GFP variants is $\mathrm{pH}$-sensitive, the shape of the GFP fluorescent spectra is relatively $\mathrm{pH}$-insensitive. This would appear to preclude the performance of the emission ratiometric measurements

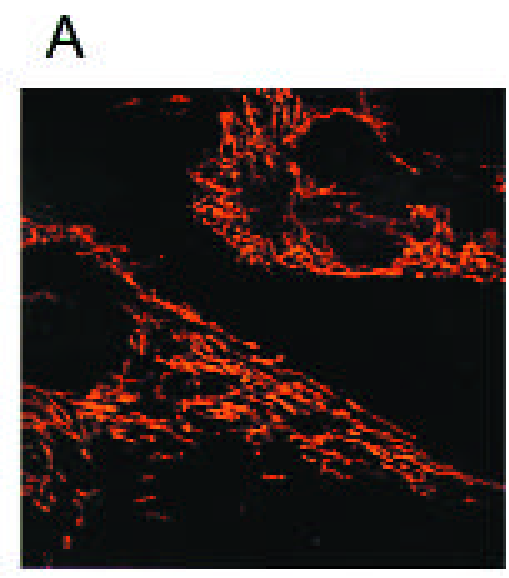

\section{B}
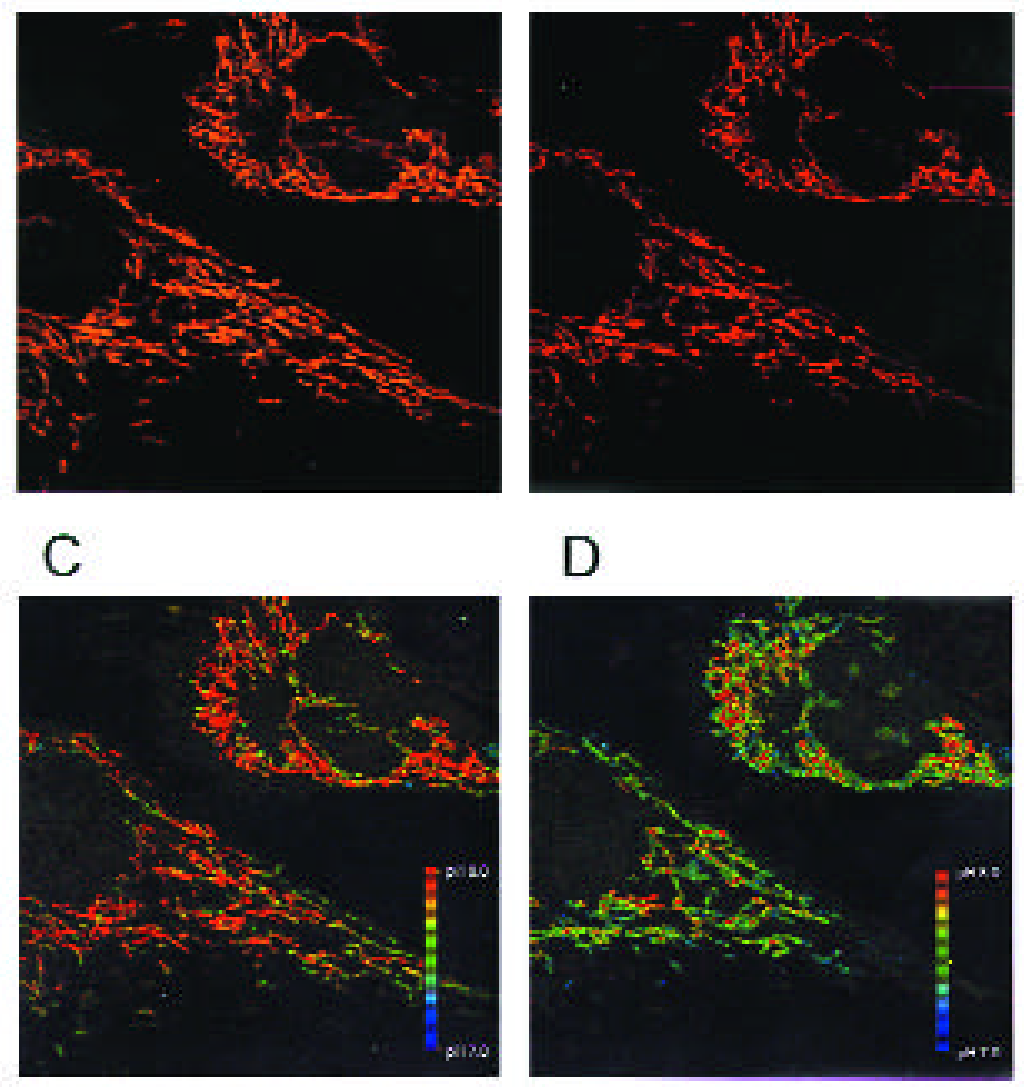

Figure 2. Selective loading of carboxy SNARF-1 into mitochondria. BHK cells were loaded with 10 $\mu \mathrm{M}$ carboxy SNARF-1/AM for $10 \mathrm{~min}$, followed by incubation for $4 \mathrm{~h}$ at room temperature. (A) Confocal image (488-nm excitation) of mitochondrial-specific loading of carboxy SNARF-1 visualized through a 560-600-nm bandpass filter. (B) Confocal image of the same cells as in A, but using a 605-nm dichroic mirror and a 610-nm longpass filter. (C) Ratio image (A and B) of mitochondria in cell pseudocolored to represent different $\mathrm{pH}$ levels. (D) Change in mitochondrial $\mathrm{pH}$ following the addition of 10 $\mu \mathrm{M}$ CCCP. Note that CCCP causes a decrease (acidification) of mitochondrial $\mathrm{pH}$.

similar to those previously described for carboxy-SNARF and other $\mathrm{pH}$-sensitive fluorophores. To address this concern, Llopis et al. (49) have applied emission ratiometry to measure $\mathrm{pH}$ in organelles using a combination of YFP and CFP. However, during the course of our studies, we observed that, when excited at $380 \mathrm{~nm}$, enhanced yellow fluorescent protein (EYFP) emission, while lower than that which occurs following excitation at $500 \mathrm{~nm}$, still occurs in a $\mathrm{pH}$-dependent manner (Figure 3B) $(24,49)$. In addition, the $\mathrm{pH}$ sensitivity of the emission of YFP when excited at $380 \mathrm{~nm}$ is opposite to that when excited at $500 \mathrm{~nm}$ (Figure 3B), suggesting that the $\mathrm{pH}$ sensitivity of the YFP-emitted fluorescence when excited at $380 \mathrm{~nm}$ is mainly caused by the effects of $\mathrm{pH}$ on the photon absorption process (40).

Because of its appropriate $\mathrm{pKa}$ and its ability to perform excitation ratiometry, we explored the use of EYFP for precise measurement of $\mathrm{pH}_{\mathrm{n}}$ (Figure 4, $\mathrm{A}$ and $\mathrm{B}$ ). Resting $\mathrm{pH}_{\mathrm{m}}$ was determined, and then the effect of the mitochondrial uncoupler, carbonyl cyanide m-chlorophenylhydrazone (CCCP), on $\mathrm{pH}_{\mathrm{m}}$ was assessed. CCCP caused a rapid acidification of $\mathrm{pH}_{\mathrm{n}}$ (Figure $4 \mathrm{C}$ ). All of the $\mathrm{pH}$ data reported here were performed with either cytosolic or mitochondrial matrix-targeted (cytochrome c oxidase subunit VIII) YFP, and the resultant image data was calibrated using a high-potassium calibration buffer containing $10 \mu \mathrm{M}$ nigericin $(13,79)$. We undertook this calibration in vivo, as previous studies have shown differences between in vivo and in vitro calibration of GFP pH indicators (71). This difference has been hypothesized to be due to the dimerization of GFPs, which can occur at high GFP protein concentrations (58).

The most significant drawback to using GFPs as indicators for the measurement of $\mathrm{pH}_{\mathrm{m}}$ is their small dynamic range at alkaline $\mathrm{pH}$ values. It has been reported that the sensitivity of recombinantly purified YFP and/or YFP expressed in cells is limited at a $\mathrm{pH}$ greater than 8.0, relative to its $\mathrm{pH}$ sensitivity at neutral or slightly acidic $\mathrm{pHs}$ (49). One of the advantages of the excitation ratiometry approach we describe here is a larger dynamic range over which $\mathrm{pH}$ measurements can be per- 
formed. Since $\Delta \mathrm{pH}_{\mathrm{m}}$ is thought to be close to 8.0, the greater $\mathrm{pH}$ sensitivity at pHs over 8.0 provided by this excitation ratiometry approach allows accurate monitoring of mitochondrial matrix $\mathrm{pH}$.

Another advantage of the ratiometric approach to ion measurement is that it can correct for differences in path length, accessible volume, and photobleaching, and thus correct for differences in YFP expression/concentration at the level of a single mitochondria (Figure 5). Ratiometry has been recognized as a useful method for correcting for differences in the concentration, pathlength, and accessible volume of several ion sensors $(8,20,22,48,75)$. Although it may be desirable to use cell lines stably expressing the protein of interest, their production can be time consuming and difficult; if primary cell cultures are being used in an experiment, then the generation of stable cell lines is not possible. Transient transfection can be used for such studies, but the level of YFP expression in each cell or even in individual mitochondria

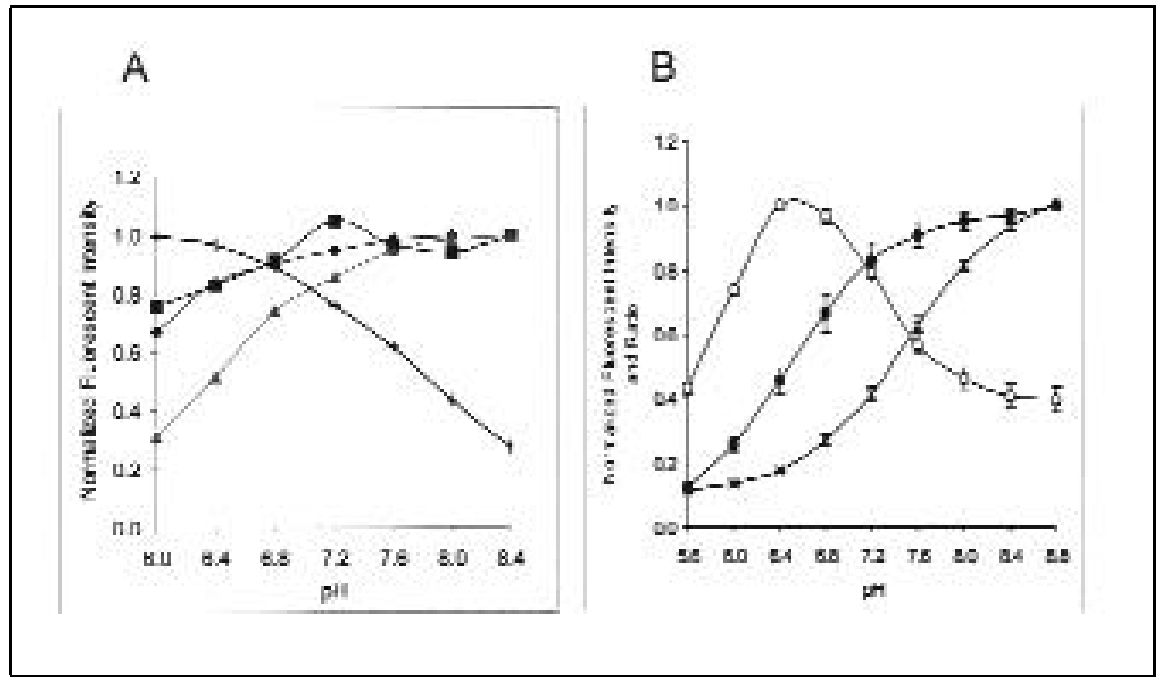

Figure 3. pH sensitivity of GFP variants determined using CLSM. (A) Cells expressing cytosolically localized GFP variants or loaded with carboxy SNARF-1/AM were incubated in buffer containing $10 \mu \mathrm{M}$ nigericin at various $\mathrm{pHs}$. The normalized fluorescent intensity (the ratio of the measured fluorescence at pH 8.4 to that at 6.0) for (+) carboxy SNARF-1, 488-nm excitation; ( $\bullet$ EGFP, 488-nm excitation; (४) EYFP, 514-nm excitation; (ם) DsRed, 568-nm excitation as a function of $\mathrm{pH}$ is shown. Note that the dynamic range in terms of the $\mathrm{pH}$ sensitivity of the GFP mutants is not as great at alkaline pHs relative to that of carboxy SNARF-1. (B) Dual-excitation ratiometry with EYFP using widefield microscopy. $\mathrm{pH}$ calibration curves were obtained in cells cytosolically expressing EYFP incubated in buffer containing $10 \mu \mathrm{M}$ nigericin. Excitation wavelengths were $485-505 \mathrm{~nm}(\bullet)$ and 370-390 nm (O). The ratio (X) represents the normalized fluorescent intensity when the EYFP is excited at $495 \mathrm{~nm}$ relative to that excitation at $380 \mathrm{~nm}$. This ratiometric approach allows quantitation of $\mathrm{pH}$ between 6.0 and 8.5 .

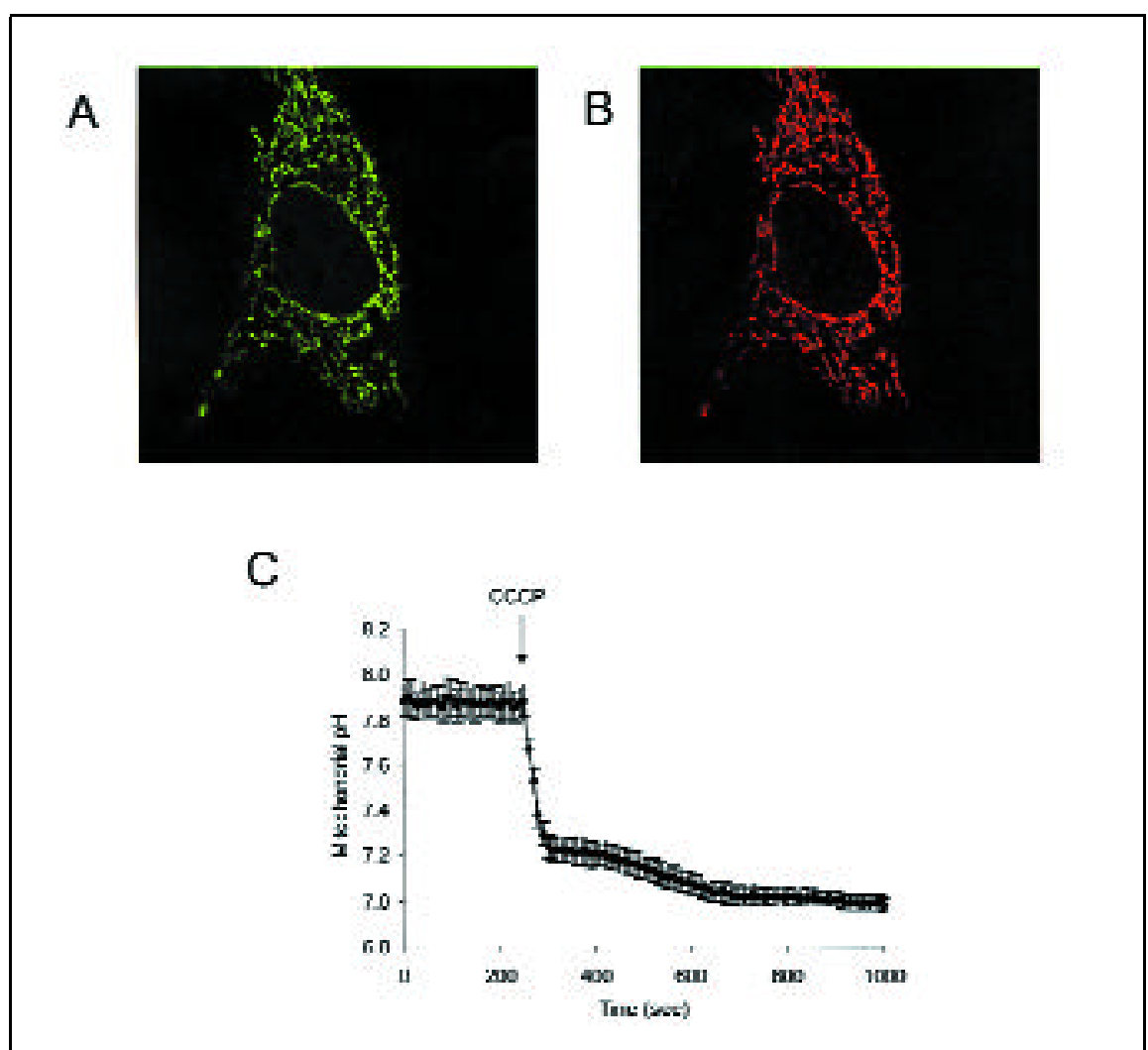

Figure 4. Measurement of $\mathrm{pH}_{\mathrm{m}}$ with mitochondrially targeted EYFP. An image of a BHK cell expressing mitochondrially targeted EYFP. (A) The cell has also been co-stained with MitoTracker Red CM-HEXros. (B) Obtained using CLSM (488 and $568 \mathrm{~nm}$; A and B). (C) Effect of $20 \mu \mathrm{M} \mathrm{CCCP}$ on pH. 

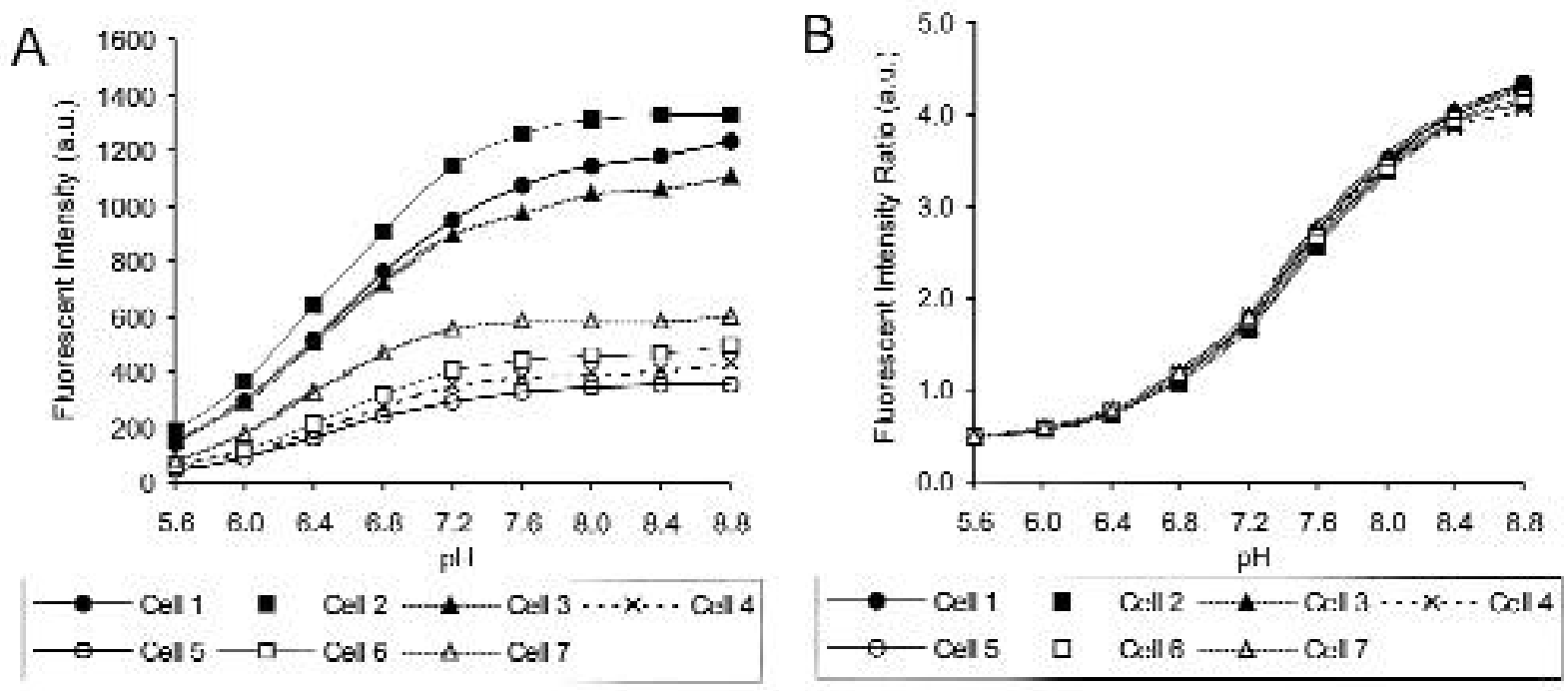

Figure 5. Correction for differences in expression level of EYFP in individual mitochondria by ratiometry. Mitochondria expressing different amounts of EYFP were incubated in calibration buffer containing $10 \mu \mathrm{M}$ nigericin. (A) Actual fluorescent intensities obtained with excitation at $495 \mathrm{~nm}$. (B) Ratio of the fluorescent intensity excited at $495 \mathrm{~nm}$ to that at $380 \mathrm{~nm}$ in the same mitochondria as shown in A. Note that ratiometry can correct for differences in the level of YFP expression between individual mitochondria in a single cell.

within a single cell may not be the same. Moreover, the level of the expressed fusion protein changes as a function of time after transfection. High transfection efficiencies can be obtained using viral vectors (i.e., adenovirus) and may be very suitable when primary cultures of cells need to be employed, yet they are still subject to the same limitations as other transfection protocols. Ratiometry can correct for these potential problems and allow for in vivo calibration in the same cell as the experimental measurement is performed. Llopis et al. (49) demonstrated that emission ratiometry with Golgitargeted EYFP and enhanced cyan fluorescent protein (ECFP) could correct for cell movement and focusing artifacts, but also reported that the ratio of EYFP to ECFP emission varied between cells because of differences in the level of expression of the two proteins (49). Dual-excitation ratiometry with YFP alone obviates this concern (Figure 5) and enables not only accurate estimation of $\mathrm{pH}_{\mathrm{n}}$ in a single cell but also comparison of $\mathrm{pH}_{\mathrm{m}}$ in several cells. Moreover, during normal or abnormal physiological functioning, mitochondrial shape, size, and volume can change drastically $(10,38,60)$. In such cases, even if the total concentration of YFP were kept constant, the relative concentration measured in the mitochondria would appear to change, resulting in misleading $\mathrm{pH}_{\mathrm{m}}$ measurements. Ratiometry should be useful in such situations because it can correct for many of these potential artifacts.

While the use of YFP excitation ratiometry has many benefits for the measurement of $\mathrm{pH}_{\mathrm{m}}$, it does requires transfection of cells with DNA containing mitochondrially targeted YFP DNA. Although numerous procedures for transfection have been established (e.g., lipofection, electroporation, and calcium phosphate co-precipitation), some cell lines are very sensitive to transfection, while other cell lines are resistant to transfection. Another potential problem of this approach is that the transfection process itself might alter cellular and mitochondrial function. Overexpression of various proteins (including GFPs) can be toxic to cells. Nevertheless, YFP excitation ratiometry is a valid approach for monitoring $\mathrm{pH}$ in not only the mitochondrial matrix but also other organelles (68). Numerous targeting sequences have been reported for use with GFP variants and other photoproteins $(9,17)$, which should provide an opportunity to monitor $\mathrm{pH}$ in a variety of different subcellular components. Moreover, because GFP fusion proteins often (although not always) maintain their functional status, (92) changes in the $\mathrm{pH}$ of the local environment of the GFP fusion protein can be evaluated during real-time physiological functioning of the protein.

Numerous variants of the GFPs with different spectra and $\mathrm{pH}$ sensitivities have already been produced, and it is expected that newly produced GFP variants will offer improvement to uses currently available and new ones in the very near future. For example, a new variant of GFP, which has a stronger emission when excited in the UV wavelength range than current GFP variants, has recently been reported (24). This particular modification is expected to decrease the cytotoxicity and autofluorescence of current UV-excited GFP variants, thereby increasing the accuracy and convenience of the ratiometry approach.

\section{REFERENCES}

1.Addanki, S., F.D. Cahill, and J.F. Sotos. 1968. Reliability of the quantitation of intramitochondrial $\mathrm{pH}$ and $\mathrm{pH}$ gradient of heart mitochondria. Anal. Biochem. 25:17-29. 
2.Bassnett, S., L. Reinisch, and D.C. Beebe. 1990. Intracellular $\mathrm{pH}$ measurement using single excitation-dual emission fluorescence ratios. Am. J. Physiol. 258:C171-C178.

3.Baysal, K., G.P. Brierley, S. Novgorodov. and D.W. Jung. 1991. Regulation of mitochondrial $\mathrm{Na}^{+} / \mathrm{Ca}^{2+}$ antiport by matrix pH. Arch. Biochem. Biophys. 291:383-389.

4.Bereiter-Hahn, J. 1990. Behavior of mitochondria in the living cell. Int. Rev. Cytol. 122:1-63.

5.Bernardi, P. 1992. Modulation of the mitochondrial cyclosporin A-sensitive permeability transition pore by the proton electrochemcal gradiant: evidence that the pore can be opened by membrane depolarization. J. Biol. Chem. 267:8834-8839.

6.Bernardi, P. 1999. Mitochondrial transport of cations: channels, exchangers, and permeability transition. Physiol. Rev. 79:1127-1155.

7.Bernardi, P., L. Scorrano, R. Colonna, V. Petronilli, and F. Di Lisa. 1999. Mitochondria and cell death: mechanistic aspects and methodological issue. Eur. J. Biochem. 264:687-701.

8.Bright, G.R., G.W. Fisher, J. Rogowska, and D.L. Taylor. 1987. Fluorescence ratio imaging microscopy: temporal and spatial measurements of cytoplasmic pH. J. Cell Biol. 104:1019-1033

9.Brini, M., P. Pinton, T. Pozzan, and R. Rizzuto. 1999. Targeted recombinant aequorins: tools for monitoring $\left[\mathrm{Ca}^{2+}\right]$ in the various com partments of a living cell. Microsc. Res. Tech. 46:380-389.

10.Camilleri-Broet, S., H. Vanderwerff, E. Caldwell, and D. Hockenbery. 1998. Distinct alterations in mitochondrial mass and function characterize different model of apoptosis. Exp. Cell Res. 239:277-292.

11.Chacon, E., H. Ohata, I.S. Harper, D.R. Trollinger, B. Herman, and J.J. Lemasters. 1996. Mitochondrial free calcium transients during excitation-contraction coupling in rabbit cardiac myocytes. FEBS Lett. 382:31-36.

12.Chacon, E., J.M. Reece, A.-L. Nieminen, G. Zahrebelski, B. Herman, and J.J. Lemasters. 1994. Distribution of electrical potential, $\mathrm{pH}$, free $\mathrm{Ca}^{2+}$, and volume inside cultured adult rabbit cardiac myocytes during chemical hypoxia: a multiparameter digitaized confocal microscopic Study. Biophys. J. 66:942-952.

13.Chaillet, J.R. and W.F. Boron. 1985. Intracellular calibration of a $\mathrm{pH}$-sensitive dye in isolated perfused salamander proximal tubules. J. Gen. Physiol. 86:765-794.

14.Chattoraj, M., B.A. King, G.U. Bublitz, and S.G. Boxer. 1996. Ultra-fast excited state dynamics in green fluorescent protein: multiple states and proton transfer. Proc. Natl. Acad. Sci. USA 93:8362-8367.

15.Chauhan, D., P. Pandey, A. Ogata, G. Teoh, N. Krett, R. Halgren, S. Rosen, D. Kufe et al. 1997. Cytochrome $c$-dependent and -independent induction of apoptosis in multiple myeloma cells. J. Biol. Chem. 272:29995-29997.

16.Davis, M.H., R.A. Altschuld, D.W. Jung, and G.P. Brierley. 1987. Estimation of intramitochondrial $\mathrm{pCa}$ and $\mathrm{pH}$ by fura- 2 and 2,7 biscarboxyethyl-5(6)0carboxyfluorescein (BCECF) fluorescence. Biochem. Biophys. Res. Com mun. 149:40-45
17.De Giorgi, F., M. Brini, C. Bastianutto, R. Marsault, M. Montero, P. Pizzo, R. Rossi, and R. Rizzuto. 1996. Targeting aequorin and green fluorescent protein to intracellular organelles. Gene 173:113-117.

18.Denk, W. 1994. Two-photon scanning photochemical microscopy: mapping ligand gated ion channel distributions. Proc. Natl. Acad. Sci. USA 91:6629-6633.

19.Deutsch, C., M. Erecinska, R. Werrlein, and I.A.Silver. 1979. Cellular energy metabolism, trans-plasma and trans-mitochondrial mem brane potential, and $\mathrm{pH}$ gradients in mouse neuroblastoma. Proc. Natl. Acad. Sci. USA 76:2175-2179.

20.Diliberto, P.A. and B. Herman. 1993. Quantitative estimation of PDGF-induced nuclear free calcium oscillations in single cells performed by confocal microscopy with fluo-3 and fura-red. Biophys. J. 64:A130.

21.Diliberto, P.A., X.F. Wang, and B. Herman. 1994. Confocal imaging of $\mathrm{Ca}^{2+}$ in cells. Method Cell Biol. 40:243-262

22.Dunn, K.W., S. Mayor, J.N. Myers, and F.R. Maxfield. 1994. Applications of ratio fluorescence microscopy in the study of cell physiology. FASEB J. 8:573-582.

23.Ellenberg, J., J. Loppincott-Schwarts, and J.F. Presley. 1999. Dual-colour imaging with GFP variants. Trends Cell Biol. 9:52-56.

24.Elsliger, M.A., R.M. Wachter, G.T. Hanson, K. Kallio, and S.J. Remington. 1999. Structural and spectral response of green fluorescent protein variants to changes in $\mathrm{pH}$. Biochem istry 38:5296-5301.

25.Errampalli, D., K. Leung, M.B. Cassidy, M. Kostrzynska, M. Blears, H. Lee, and J.T. Trevors. 1999. Applications of the green fluorescent protein as a molecular marker in environmental microorganisms. J. Microbiol. Methods 35:187-199.

26.Eskes, R., B. Antonsson, A. Osen-Sand, S. Montessuit, C. Richter, R. Sadoul, G. Mazzei, A. Nichols et al. 1998. Bax-induced cytochrome $\mathrm{C}$ release from mitochondria is independent of the permeability transition pore but highly dependent on $\mathrm{Mg}^{2}+$ ions. J. Cell Biol. 143:217-224.

27.Garner, D.L., C.A. Thomas, H.W. Joerg, J.M. DeJarnette, and C.E. Marshall. 1997. Fluorometric assessments of mitochondrial function and viability in cryopreserved bovine spermatozoa. Biol. Reprod. 57:1401-1406.

28.Gerdes, H.H. and C. Kaether. 1996. Green fluorescent protein: applications in cell biology. FEBS Lett. 389:44-47.

29.Gottlieb, R.A. 1999. Mitochondria: ignition chamber for apoptosis. Mol. Genet. Metab. 68:227-231.

30.Halestrap, A.P. 1978. Pyruvate and ketonbody transport across the mitochondrial mem brane: exchange properties, $\mathrm{pH}$-dependence and mechanism of the carrier. Biochem. $\mathrm{J}$. 172:377-387.

31.Haupts, U., S. Maiti, P. Schwille, and W.W. Webb. 1998. Dynamics of fluorescence fluctuations in green fluorescent protein observed by fluorescence correlation spectroscopy. Proc. Natl. Acad. Sci. USA 95:13573-13578

32.Haworth, R.A. and D.R. Hunter. 1979. The $\mathrm{Ca}^{2+}$-induced membrane transient in mitochondria: II. nature of the $\mathrm{Ca}^{2}+$ trigger site.
Arch. Biochem. Biophys. 195:460-467

33.Heiskanen, K.M., M.B. Bhat, H.W. Wang, J. Ma, and A.-L. Nieminen. 1999. Mitochondrial deporalization accompanies cytochrome $\mathrm{c}$ release during apoptosis in PC6 cells. J. Biol. Chem. 274:5654-5658.

34.Heldt, H.W., K. Werden, M. Milovancev, and G. Geller. 1973. Alkalization of the chloroplast stroma caused by light-dependent proton flux into the thylakoid space. Biochim. Biophys. Acta 314:224-241.

35.Herrmann, J.M. and W. Neupert. 2000. Protein transport into mitochondria. Curr. Opin. Microbiol. 3:210-214.

36.Hoek, J.B., D.G. Nicholls, and J.R. William son. 1980. Determination of mitochondrial protonmotive force in isolated hepatocytes. J. Biol. Chem. 255:1458-1464.

37.Jung, D.M., M.H. Davis, and G.P. Brierley. 1989. Estimation of matrix $\mathrm{pH}$ in isolated heart mitochondria using a fluorescent probe. Anal. Biochem. 178:348-354.

38.Karbowski, M., C. Kurono, Y. Nishizawa, Y. Horie, T. Soji, and T. Wakabayashi. 1997. Induction of megamitochondria by some chemicals inducing oxidative stress in primary cultured rat hepatocytes. Biochim. Biophys. Acta 1349:242-250.

39.Kluck, R.M., E. Bossy-Wetzel, D.R. Green, and D.D. Newmeyer. 1997. The release of cytochrome $\mathrm{c}$ from mitochondria: a primary site for bcl-2 regulation of apoptosis. Science 275:1132-1136.

40.Kneen, M., J. Farinas, Y. Li, and A.S. Verkman. 1998. Green fluorescent protein as a noninvasive intracellular $\mathrm{pH}$ indicator. Biophys. J. 74:1591-1599.

41.Kroemer, G. 1999. Cytochrome c. Curr. Biol. 9:R468.

42.LaNoue, K.F. and A.C. Schoolwerth. 1979 Metabolite transport in mitochondria. Ann. Rev. Biochem. 48:871-922.

43.LaNoue, K.F., T. Strzelecki, and F. Finch 1984. The effect of glucagon on hepatic respiratory capacity. J. Biol. Chem. 259:4116-4121.

44.Leffel, S.M., S.A. Mabon, and C.N.J. Stew art. 1997. Applications of green fluorescent protein in plants. BioTechniques 23:912-918.

45.Lemasters, J.J., E. Chacon, H. Ohata, I.S. Harper, A.-L. Nieminen, S. Tesfai, and B. Herman. 1995. Measurement of electrical potential, $\mathrm{pH}$, and free calcium ion concentration in mitochondria of living cells by laser scanning confocal microscopy. Method Enzymol. 260:428-444

46.Lemasters, J.J., A.-L. Nieminen, T. Qian, L.C. Trost, S.P. Elmore, Y. Nishimura, R.A. Crowe, W.E. Cascio et al. 1998. The mitochondrial permeability transition in cell death: a common mechanism in necrosis, apoptosis and autophagy. Biochem. Biophys. Acta 1366:177-196.

47.Lemasters, J.J., A.-L. Nieminen, T. Qian, L.C. Trost, and B. Herman. 1997. The mitochondrial permeability transition in toxic, hypoxic and reperfusion injury. Mol. Cell. Biochem. 174:159-165.

48.Lipp, P. and E. Niggli. 1993. Ratiometric confocal $\mathrm{Ca}^{2+}$-measurements with visible wavelength indicators in isolated cardiac myocytes. Cell Calcium 14:359-372.

49.Llopis, J., J.M. McCaffery, A. Miyawaki, 
M.G. Farquhar, and R. Tsien. 1998. Measurement of cytosolic, mitochondrial, and Golgi $\mathrm{pH}$ in single living cells with green fluorescent proteins. Proc. Natl. Acad. Sci. USA 95:6803-6808

50.Miesenbšck, G., D.A. De Angelis, and J.E. Rothman. 1998. Visualizing secretion and synaptic transmission with $\mathrm{pH}$-sensitive green fluorescent proteins. Nature 394:192-195.

51.Minta, A., J.P. Kao, and R.Y. Tsien. 1989. Fluorescent indicators for cytosolic calcium based on rhodamine and fluorescein chromophores. J. Biol. Chem. 264:8171-8178.

52.Misteli, T. and D.L. Spector. 1997. Applications of the green fluorescent protein in cell biology and biotechnology. Nat. Biotechnol. 15:961-964.

53.Miyata, H., H.S. Silverman, S.J. Sollott, E.G. Lakatta, M.D. Stern, and R.G. Hansford. 1991. Measurement of mitochondrial free $\mathrm{Ca}^{2+}$ concentration in living single rat cardiac myocytes. Am. J. Physiol. 261:H1123H1134.

54.Miyawaki, A., O. Griesbeck, R. Heim, and R.Y. Tsien. 1999. Dynamic and quantitative $\mathrm{Ca}^{2}+$ measurements using improved cameleons. Proc. Natl. Acad. Sci. USA 96:2135-2140.

55.Miyawaki, A., J. Llopsi, R. Heim, J.M. McCaffery, J.A. Adams, M. Ikura, and R.Y. Tsien. 1997. Fluorescent indicators for $\mathrm{Ca}^{2+}$ based on green fluorescent proteins and calmodulin. Nature 388:882-887.

56.Nicholls, D.G. 1974. The influence of respiration and ATP hydrolysis on the proton-electrochemical gradient across the inner membrane of rat-liver mitochondria as determined by ion distribution. Eur. J. Biochem. 50:305-315.

57.Niwa, H., S. Inouye, T. Hirano, T. Matsuno, S. Kojima, M. Kubota, M. Ohashi, and F.I. Tsuji. 1996. Chemical nature of the light emitter of Aequorea green fluorescent protein. Proc. Natl. Acad. Sci. USA 93:13617-13622.

58.Palm, G.J., A. Zdanov, G.A. Gaitanaris, R. Stauber, G.N. Pavlakis, and A. Wlodawer. 1997. The structural basis for spectral variations in green fluorescent protein. Nat. Struct. Biol. 4:361-365.

59.Patterson, G.H., S.M. Knobel, W.D. Sharif, S.R. Kain, and D.W. Piston. 1997. Use of the green fluorescent protein and its mutants in quantitative fluorescence microscopy. Biophys. J. 73:2780-2782.

60 Pawley, J. 2000. The 39 steps: a cautionary tale of quantitative 3-D fluorescence microscopy. BioTechniques 28:884-887.

61.Persechini, A., J.A. Lynch, and V.A. Romoser. 1997. Novel fluorescent indicator proteins for monitoring free intracellular $\mathrm{Ca}^{2+}$. Cell Calcium 22:209-216.

62.Petronilli, V., C. Cola, and P. Bernardi. 1993. Modulation of the mitochondrial cyclosporin A-sensitive permeability transition pore: II. the minimal requirements for pore induction underscore a key role for transmembrane electrical potential, matrix $\mathrm{pH}$, and matrix $\mathrm{Ca}^{2}$. $\mathrm{J}$. Biol. Chem. 268:1011-1016.

63.Piston, D.W., M.S. Kirby, H. Cheng, W.J. Lederer, and W.W. Webb. 1994. Two-photonexcitation fluorescence imaging of three-dimensional calcium-ion activity. Applied Optics 33:662-669.

64.Pollok, B.A. and R. Heim. 1999. Using GFP in FRET-based applications. Trends Cell Biol. 9:57-60.

65.Prpic, V., T.L. Spencer, and F.L. Bygrave. 1978. Stable enhancement of calcium retention in mitochondria isolated from rat liver after the administration of glucagon to the intact animal. Biochem. J. 176:705-714.

66.Rizzuto, R., C. Bastianutto, M. Brini, M. Murgia, and T. Pozzan. 1994. Mitochondrial $\mathrm{Ca}^{2+}$ homeostasis in intact cells. J. Cell Biol. 126:1183-1194.

67.Rizzuto, R., M. Brini, M. Murgia, and T. Pozzan. 1993. Microdomines with high $\mathrm{Ca}^{2+}$ close to IP3-sensitive channels that are sensed by neighboring mitochondria. Science 262 : 744-747.

68.Rizzuto, R., P. Pinton, W. Carrington, F.S. Fay, K.E. Fogarty, L.M. Lifshitz, R.A. Tuft, and T. Pozzan. 1998. Close contacts with the endoplasmic reticulum as determinants of mitochondrial $\mathrm{Ca}^{2+}$ responses. Science 280:17631766.

69.Rizzuto, R., A.W.M. Simpson, M. Brini, and T. Pozzan. 1992. Rapid changes of mitochondrial $\mathrm{Ca}^{2+}$ revealed by specifically targeted recombinant aequorin. Nature 358:325-327.

70.Robb-Gaspers, L.D., P. Burnett, G.A. Rutter, R.M. Denton, R. Rizzuto, and A.P. Thomas. 1998. Integrating cytosolic calcium signals into mitochondrial metabolic responses. EMBO J. 17:4987-5000.

71.Robey, R.B., O. Ruiz, A.V. Santos, J. Ma, F. Kear, L.-J. Wang, C.J. Li, A.A. Bernardo et al. 1998. pH-dependent fluorescence of a heterogously expressed Aequorea green fluorescent protein mutant: in situ spectral characteristics and applicability to intracellular $\mathrm{pH}$ estimation. Biochemistry 37:9894-9901.

72.Roe, M.W., J.J. Lemasters, and B. Herman. 1990. Assessment of Fura-2 for measurements of cytosolic free calcium. Cell Calcium 11:6373.

73.Romoser, V.A., P.M. Hinkle, and A. Persechini. 1997. Detection in living cells of $\mathrm{Ca}^{2+}$ dependent changes in the fluorescence emission of an indicator composed of two green fluorescent protein variants linked by a calmodulin-binding sequence. J. Biol. Chem. 272:13270-13274.

74.Shimizu, S., Y. Eguchi, W. Kamiike, Y. Funahashi, A. Mignon, V. Lacronique, H. Matsuda, and Y. Tsujimoto. 1998. Bcl-2 prevents apoptotic mitochondrial dysfunction by regulating proton flux. Proc. Natl. Acad. Sci. USA 95:1455-1459.

75.Silver, R.B. 1998. Ratio imaging: practical considerations for measuring intracellular calcium and $\mathrm{pH}$ in living tissue. Method Cell Biol. 56:237-251.

76.Steinberg, S.F., J.P. Bilezikian, and Q. AlAwqati. 1987. Fura-2 fluorescence is localized to mitochondria in endothelial cells. Am. J. Physiol. 253:C744-C747.

77.Strzelecki, T., J.A. Thomas, C.D. Koch, and K.F. LaNoue. 1984. The effect of hormones on proton compartmentation in hepatocytes. J. Biol. Chem. 259:4122-4129.

78.Thomas, J.A. 1986. Intracellularly trapped $\mathrm{pH}$ indicators. Soc. Gen. Physiol. Ser. 40:311-325.

79.Thomas, J.A., R.N. Buchsbaum, A. Zimniak, and E. Racker. 1979. Intracellular $\mathrm{pH}$ measurements in Ehrlich ascites tumor cells utilizing spectroscopic probes generated in situ. Biochemistry 18:2210-2218

80.Thomas, P.J., L.D. Gaspers, C. Pharr, and J.A. Thomas. 1991. Continuous measurement of mitochondrial $\mathrm{pH}$ gradients in isolated hepatocytes by difference ratio spectroscopy. Arch. Biochem. Biophys. 288:250-260.

81.Trollinger, D.R., W.E. Cascio, and J.J. Lemasters. 1997. Selective loading of rhod-2 into mitochondria shows mitochondrial $\mathrm{Ca}^{2+}$ transients during the contractile cycle in adult rabbit cardiac myocytes. Biochem. Biophys. Res. Commun. 236:738-742.

82.Tsien, R.Y. 1998. The green fluorescent protein. Annu. Rev. Biochem. 67:509-544.

83.Vassella, E., K. Straesser, and M. Boshart. 1997. A mitochondrion-specific dye for multicolour fluorescent imaging of Trypanosoma brucei. Mol. Biochem. Parasitol. 90:381-385.

84.Wachter, R.M., M.A. Elsliger, K. Kallio, G.T. Hanson, and S.J. Remington. 1998. Structural basis of spectral shifts in the yellowemission variants of green fluorescent protein. Structure 6:1267-1277.

85.Wallace, K.B., J.T. Eells, V.M.C. Madeira, G. Cortopassi, and D.P. Jones. 1997. Mitochondria-mediated cell injury. Fundam. Appl. Toxicol. 38:23-37.

86.Ward, W.W. and S.H. Bokman. 1982. Reversible denaturation of Aequorea green-fluorescent protein: physical separation and characterization of renatured protein. Biochemistry 21:4535-4540.

87.Ward, W.W., C.W. Cody, R.C. Hart, and M.J. Cormier. 1980. Spectrophotometric identity of the energy transfer chromophores in Renilla and Aequorea green-fluorescent protein. Photochem. Photobiol. 31:611-615.

88. Ward, W.W., H.J. Prentice, A.F. Roth, C.W. Cody, and S.C. Reeves. 1982. Spectral perturbations of the Aequorea green-fluorescent protein. Photochem. Photobiol. 35:803-808.

89. Waterhouse, N.J. and D.R. Green. 1999. Mitochondria and apoptosis: HQ or high-security prison? J. Clin. Immunol. 19:378-387.

90. Yang, J., X. Liu, K. Bhalla, C.N. Kim, A.M. Ibrado, J. Cai, T.I. Peng, D.P. Jones et al. 1997. Prevention of apoptosis by bcl-2: release of cytochrome c from mitochondria blocked. Science 275:1129-1132.

91.Zamzami, N., P. Marchetti, M. Castedo, D. Decaudin, A. Macho, T. Hirsch, S.A. Susin, P.X. Petit et al. 1995. Sequential reduction of mitochondrial transmembrane potential and generation of reactive oxygen species in early programmed cell death. J. Exp. Med. 182:367377.

92.Zhang, Y., J.J. Lemasters, and B. Herman. 1999. Secretory group IIA phospholipase A2 generates anti-apoptotic survival signals in kidney fibroblasts. J. Biol. Chem. 274:2772627733.

\section{Address correspondence to:}

Dr. Brian Herman

Department of Cellular \& Structural Biology

University of Texas HSC at San Antonio

7703 Floyd Curl Drive

San Antonio, TX 78229-3900, USA

e-mail: hermanb@uthscsa.edu 